University of Nebraska - Lincoln

DigitalCommons@University of Nebraska - Lincoln

Faculty Papers and Publications in Animal

Science

Animal Science Department

1995

\title{
Uterine Mass and Uterine Blood Volume in Mice Selected 21 Generations for Alternative Criteria to Increase Litter Size
}

\author{
Merlyn K. Nielsen \\ University of Nebraska-Lincoln, mnielsen1@unl.edu \\ R. J. Kittok \\ University of Nebraska-Lincoln, rkittok1@aol.com \\ Y. L. Kochera Kirby \\ University of Nebraska-Lincoln
}

Follow this and additional works at: https://digitalcommons.unl.edu/animalscifacpub

Part of the Animal Sciences Commons

Nielsen, Merlyn K.; Kittok, R. J.; and Kochera Kirby, Y. L., "Uterine Mass and Uterine Blood Volume in Mice Selected 21 Generations for Alternative Criteria to Increase Litter Size" (1995). Faculty Papers and Publications in Animal Science. 491.

https://digitalcommons.unl.edu/animalscifacpub/491

This Article is brought to you for free and open access by the Animal Science Department at DigitalCommons@University of Nebraska - Lincoln. It has been accepted for inclusion in Faculty Papers and Publications in Animal Science by an authorized administrator of DigitalCommons@University of Nebraska - Lincoln. 


\title{
Uterine Mass and Uterine Blood Volume in Mice Selected 21 Generations for Alternative Criteria to Increase Litter Size ${ }^{1}$
}

\author{
M. K. Nielsen ${ }^{2}$, R. J. Kittok, and Y. L. Kochera Kirby ${ }^{3}$ \\ Department of Animal Science, University of Nebraska-Lincoln, Lincoln 68583-0908
}

\begin{abstract}
Lines of mice, selected for 21 generations using alternative criteria to increase litter size, were evaluated for uterine mass and uterine blood volume to help explain differences in uterine capacity. For this study, mice were sampled from Generation 27 , the sixth generation after relaxation of selection. Mice came from all four criteria of selection (LS = selection on number born to unaltered females; IX = selection on an index of ovulation rate and ova success; UT = selection on uterine capacity; and LC = unselected control) in each of three replicates (a total of 12 lines). Measurement was at one of two stages,
\end{abstract}

either $3 \mathrm{~d}$ or $6 \mathrm{~d}$ of gestation. Matings were at $10 \mathrm{wk}$ of age, and a total of 508 mice ( 17 to 26 per line-day of pregnancy subclass) were measured. The mean of the three selected groups exceeded the control in uterine mass $(P<.001)$, uterine blood volume $(P<.002)$, uterine mass/body mass $(P<.03)$, and uterine blood volume/body mass $(P<.04)$ but not in uterine blood volume/uterine mass. Greater uterine mass and concomitantly greater uterine blood volume may have been partly responsible for greater uterine capacity resulting from LS, IX, and UT selections.

Key Words: Mice, Selection, Litter Size, Uterine Capacity, Blood Volume

J. Anim. Sci. 1995. 73:2243-2248

\section{Introduction}

Litter size is a complex phenomenon, determined by several components. Selection to increase litter size has been successful in mice (Joakimsen and Baker, 1977; Bakker et al., 1978), and responses result from improvements in more than one of the limiting components. Bennett and Leymaster (1989) have described litter size in swine from the joint distribution of number of potentially viable embryos and uterine capacity. A parallel model can be imagined for describing litter size in mice. Physiological explanations for the variability in uterine capacity need elucidation.

A mouse experiment at the University of Nebraska (Clutter et al., 1990; Gion et al., 1990; Kirby and Nielsen, 1993), designed to evaluate selection for the components of litter size, has produced significant responses in the components, and hence in litter size.

\footnotetext{
${ }^{1}$ Published as paper no. 10824, Journal Series, Agric. Res. Div., Univ. of Nebraska, Lincoln 68583-0908.

${ }^{2}$ To whom correspondence should be addressed: A218 Animal Sciences.

${ }^{3}$ Present address: Dept. of Poult. Sci., Univ. of Arkansas, Fayetteville 72701.

Received September 22, 1994.

Accepted March 31, 1995
}

Clutter et al. (1994) reported a significant general response in uterine capacity, measured as the number of fetuses in unilaterally ovariectomized females, following selection for each criterion in the experiment. Al-Shorepy et al. (1992) studied pre-implantation embryonic development and found that stage of development within a litter was more advanced and less variable at $d 3.5$ of gestation in the Nebraska selection lines. The objective of the present study was to determine whether differences in uterine mass and uterine blood volume exist in these selected lines, offering some physiological explanation for differences observed in uterine capacity.

\section{Materials and Methods}

Experimental Animals. Mice for the present study came from 12 different lines; the 12 lines were from three replicates of four different selection criteria. All four criteria were represented in each of the three replicates. The population and selection process have been described earlier (Clutter et al., 1990; Gion et al., 1990; Kirby and Nielsen, 1993). Briefly, the four criteria were: 1) LS: selection on number born to unaltered females; 2) IX: selection on an index of components of litter size $\{I=1.21 \times$ ovulation rate + $9.05 \times$ ova success (proportion of ova represented by pups born)\}; 3 ) UT: selection on number born to 
unilaterally ovariectomized females; and 4) LC: unselected control.

Selection proceeded for 21 generations and then ceased. The rationale for the selection criteria have been described previously (Clutter et al., 1990), as well as response in litter size through 13 generations (Gion et al., 1990) and 21 generations (Kirby and Nielsen, 1993). An evaluation of uterine capacity, measured as the number of fetuses at $d \mathbf{1 7}$ of gestation in either the left or right uterine horn of unilaterally ovariectomized females at Generations 22 and 23 (Clutter et al., 1994), and an evaluation of preimplantation embryonic development at Generation 27 has occurred (Al-Shorepy et al., 1992). After Generation 21, the lines have been maintained with 32 pairs of parents each generation. The mice for the present study came from Generation 27 (sixth generation of relaxed selection) and were littermates to those in the study of pre-implantation embryonic development (Al-Shorepy et al., 1992).

Experimental Procedure. Females were mated to males of their own line at $10 \mathrm{wk}$ of age. Females were checked for mating plugs each morning, and after confirmation of mating they were randomly assigned within line to either measurement at $d 3$ or $d 6$ of pregnancy (observed mating plug $=\mathrm{d} 0$ ). These two stages of gestation were chosen to give points just before implantation ( $\mathrm{d} 3$ ) and following implantation (d 6).

Each female mouse was immediately weighed after it was euthanatized by asphyxiation with carbon dioxide. Then, the mouse's abdomen was opened by incision and the vasculature of the uterus clamped and the uterus excised. The uterus was blotted to remove incidental blood and placed in a previously weighed tube containing $2.0 \mathrm{~mL}$ of $.05 \quad M$ tris(hydroxymethyl)aminomethane (Tris) buffer, $\mathrm{pH}$ 7.4, and weight of the uterus was obtained. The ovaries were excised and the number of corpora lutea were counted under $10 \times$ magnification with the aid of dissection. A blood sample was drawn by cardiac puncture and an aliquot was transferred to a heparinized capillary tube for determination of the packed cell volume. Numbers of animals measured in each selection criterion and on each day of gestation are shown in Table 1; a total of 508 mice were used.
The uterus of each mouse was homogenized in the $2.0 \mathrm{~mL}$ of Tris buffer in a glass tube homogenizer fitted with a Teflon pestle connected to an electric stirrer. The tissue was homogenized for $60 \mathrm{~s}$ at 5,000 $\mathrm{rpm}$. The homogenized tissue was transferred to a 1.5-mL microcentrifuge tube and centrifuged for 15 $\min$ at $15,000 \times \mathrm{g}$. The supernatant was stored at $-20^{\circ} \mathrm{C}$ until blood volume of the uterus was calculated from spectrophotometric determination of hemoglobin content. The procedure for measurement of hemoglobin was previously described by Tanaka et al. (1989). Briefly, absorbance of the supernatant of the homogenate was measured at 380,414 , and $448 \mathrm{~nm}$ with a spectrophotometer (Shimadzu, Model UV-260, Columbia, MD). The optical densities of proteins other than hemoglobin were corrected by the subtraction of the average of the absorbance at 380 and $447 \mathrm{~nm}$ from the absorbance at $414 \mathrm{~nm}$. This correction formula was also used to calculate the amount of hemoglobin present in various volumes of a pool of mouse blood that was used to generate standard curves for the assay. The intra- and interassay coefficients of variation were .8 and $3.0 \%$, respectively, for this procedure.

Data Analyses. Body mass, number of corpora lutea, uterine mass, uterine blood volume (unadjusted and adjusted to a standard packed cell volume equal to the mean of $52 \%$ ), and the ratios of uterine mass to body mass, uterine blood volume to body mass, and uterine blood volume to uterine mass were analyzed with procedures for a fixed linear model that included the effects of day of gestation, selection criterion, replicate, and all interactions. Because uterine mass doubles between $\mathrm{d} 3$ and $\mathrm{d} 6$, the variance for uterine mass and the ratio of uterine mass to body mass were much larger at $d 6$ than at $d 3$. These two variables were also analyzed after a square-root transformation that successfully equalized the variances across the $2 \mathrm{~d}$.

All variables noted above, except number of corpora lutea, were also analyzed in two data sets (mice measured at $d$ or at $d$ of gestation) using procedures for a fixed linear model with the effects of selection criterion, replicate, and replicate $\times$ criterion interaction plus number of corpora lutea as a covariable to adjust to the same number of ovulations. This additional analysis was used to adjust the variables to the unobservable situation of all mice having the same

Table 1. Number of animals measured by replicate, selection criterion, and day of pregnancy

\begin{tabular}{|c|c|c|c|c|c|c|c|c|}
\hline \multirow[b]{2}{*}{ Replicate } & \multicolumn{4}{|c|}{ Day 3} & \multicolumn{4}{|c|}{ Day 6} \\
\hline & $\mathbf{L X}^{\mathbf{a}}$ & LS & UT & LC & IX & $\mathrm{LS}$ & UT & LC \\
\hline 1 & 18 & 17 & 22 & 23 & 17 & 21 & 17 & 17 \\
\hline 2 & 22 & 21 & 25 & 20 & 24 & 19 & 23 & 23 \\
\hline 3 & 24 & 24 & 25 & 20 & 22 & 21 & 26 & 17 \\
\hline
\end{tabular}

${ }^{\mathrm{a}} \mathrm{DX}$ = index; LS = litter size; UT = uterine capacity; LC = control. 
number of ovulations, to give some insight into whether number of ovulations influences uterine physiology. The data were analyzed separately by the two stages of gestation because we expected the magnitude of the regression coefficients to be quite different before and after implantation.

For tests of significance, effects of replicates were assumed random. Thus, differences among selection criteria were tested with the replicate $x$ criterion interaction as the error term, day differences were tested with replicate $x$ day interaction as the error term, and the criterion $x$ day interaction was tested with replicate $x$ criterion $x$ day interaction. Orthogonal contrasts were used to further evaluate any criterion differences. These contrasts were as follows: 1) LS, IX, UT vs LC, to test the general effect of selection; 2) LS, IX vs UT, to test whether selection to increase "total litter size" is different from selection on only uterine capacity; and 3) LS vs IX, to test the difference between methods to increase litter size.

\section{Results and Discussion}

Differences in Selection Criteria. Probabilities of significant differences due to selection criterion, day of pregnancy, and criterion $x$ day interaction are shown in Table 2. Table 2 also contains the mean squares for testing each effect and interaction. Analyses of uterine blood volume as measured for each mouse, or when adjusted to a packed cell volume of $52 \%$, produced very similar results because there was little variability in the hematocrit. For simplicity, only uterine blood volume as measured and not corrected for packed cell volume will be presented and discussed.

Selection produced highly significant (highest probability of type I error was .005) differences in body mass, uterine mass, corpora lutea, and uterine blood volume. Less significant differences were found for uterine mass relative to body mass $(P<.09)$ and uterine blood volume per unit of body mass $(P<.11)$. There were no differences between selection criteria for uterine blood volume per unit of uterine mass. Significance of the tests for selection criterion effects were the same whether or not uterine mass and uterine mass/body mass were transformed before analysis.

Least squares means by selection criterion and probabilities of significance for linear contrasts of the means are shown in Table 3. The overall effect of selection (IX, LS, UT vs LC) was significant (highest probability of type I error was .04) for all measurements except uterine blood volume per unit of uterine mass. For the comparison of IX and LS vs UT selection, no significant differences were found for uterine mass relative to body mass or uterine blood volume relative to body or uterine mass. However, body mass, uterine mass, number of corpora lutea, and uterine blood volume were greater (probability of type I error no larger than .03) for the average of responses to IX and LS selection as compared to UT selection. Comparisons between IX and LS selection were significant $(P<.03)$ for number of corpora lutea; differences in the transformed uterine mass $(P<.14)$ and uterine mass/body mass $(P<.20)$ approached significance and were similar to the untransformed results.

Differences in Day of Pregnancy. Day 3 vs d 6 of pregnancy significantly affected (probability of type I error no larger than .03) all measurements except number of corpora lutea (Table 2). Any differences in number of corpora lutea due to day of pregnancy would be purely due to chance in sampling animals at the two times. Least squares means for each day of pregnancy are shown in Table 4 .

As expected, body mass, uterine mass, and uterine blood volume increased from $\mathrm{d} 3$ to $\mathrm{d} 6$. Mean uterine mass almost doubled from $\mathrm{d} 3$ to $\mathrm{d} 6$ (.207 increased to $.409 \mathrm{~g}$ ). Uterine mass relative to body mass increased, as did uterine blood volume per unit of body mass;

Table 2. Significance levels for differences due to selection criterion, day of pregnancy, and selection criterion $x$ day of pregnancy and mean squares used as error terms

\begin{tabular}{|c|c|c|c|c|c|c|}
\hline Item & Criterion & Day & Criterion $\times$ day & $\mathrm{R} \times \mathrm{C}$ & $\mathrm{R} \times \mathrm{D}$ & $\mathrm{R} \times \mathrm{C} \times \mathrm{D}$ \\
\hline Uterine mass, $\mathrm{g}$ & .004 & .01 & .11 & .0114 & .0015 & .0120 \\
\hline $\operatorname{Tr}^{b}$ uterine mass, $g$ & .004 & .001 & .32 & .0091 & .0048 & .0089 \\
\hline Corpora lutea & .004 & .48 & .07 & 30.21 & 13.27 & 5.15 \\
\hline Uterine blood, $\mu \mathrm{L}$ & .004 & .002 & .67 & 20.00 & 7.52 & 28.79 \\
\hline Uterine blood/body mass, $\mu \mathrm{L} / \mathrm{g}$ & .11 & .002 & .96 & .0291 & .0099 & .077 \\
\hline Uterine blood/uterine mass, $\mu \mathrm{L} / \mathrm{g}$ & .87 & .03 & .19 & 502.5 & 267.8 & 73.5 \\
\hline
\end{tabular}

${ }^{a} \mathrm{R} \times \mathrm{C}=$ replicate $\times$ criterion, error for criterion differences, $\mathrm{R} \times \mathrm{D}=$ replicate $\times$ day, error for day differences; $\mathrm{R} \times \mathrm{C} \times \mathrm{D}:$ replicate $\times$ criterion $\times$ day, error for criterion $x$ day interaction.

$\mathrm{b}_{\mathrm{Tr}}=$ square-root transformation of the variable. 
Table 3. Least squares means by selection criterion, SE of the means, and significance levels of contrasts of the criterion means

\begin{tabular}{|c|c|c|c|c|c|c|c|c|}
\hline \multirow[b]{2}{*}{ Item } & \multicolumn{4}{|c|}{ Criterion $^{\mathrm{a}}$} & \multirow[b]{2}{*}{ SEM } & \multicolumn{3}{|c|}{ Significance level of contrast ${ }^{b}$} \\
\hline & IX & LS & UT & $\mathrm{LC}$ & & 1 & 2 & 3 \\
\hline Body mass, g & 28.75 & 28.96 & 26.91 & 25.30 & .42 & .001 & .008 & .74 \\
\hline Uterine mass, $\mathrm{g}$ & .323 & .348 & .303 & .258 & .010 & .001 & .03 & .12 \\
\hline $\operatorname{Tr}^{\mathrm{c}}$ uterine mass, $\mathrm{g}$ & .557 & .577 & .540 & .500 & .009 & .001 & .04 & .14 \\
\hline Corpora lutea & 14.87 & 16.94 & 13.95 & 12.40 & .50 & .003 & .02 & .03 \\
\hline Uterine blood, $\mu \mathrm{L}$ & 13.80 & 14.32 & 12.53 & 10.88 & .40 & .002 & .02 & .39 \\
\hline Uterine mass/body mass, $\%$ & 1.11 & 1.19 & 1.11 & 1.01 & .04 & .03 & .40 & .20 \\
\hline $\operatorname{Tr}$ uterine mass/body mass, $\%$ & .104 & .107 & .104 & .099 & .002 & .03 & .47 & .20 \\
\hline Uterine blood/body mass, $\mu \mathrm{L} / \mathrm{g}$ & .476 & .492 & .459 & .428 & .015 & .04 & .21 & .50 \\
\hline Uterine blood/uterine mass, $\mu \mathrm{L} / \mathrm{g}$ & 44.17 & 42.83 & 41.88 & 43.10 & 2.03 & .95 & .52 & .66 \\
\hline
\end{tabular}

${ }^{\text {a }} \mathrm{IX}=$ index; LS = litter size; UT = uterine capacity; LC = control.

bContrasts: 1) IX, LS, UT vs LC; 2) IX, LS vs UT; 3) IX vs LS.

${ }^{c} \mathrm{Tr}=$ square-root transformation of the variable.

however, uterine blood per unit of uterine mass decreased with increasing length of pregnancy.

Selection Criterion $\times$ Day of Pregnancy Interaction. Although the test for a criterion $\times$ day interaction approached significance (Table $2, P<.07$ ), there is no biological explanation other than chance in sampling of mice at the two stages of pregnancy. When analyzing uterine mass without transformation, there was an indication $(P<.11)$ that mice from the different selection criteria perhaps responded differently from $\mathrm{d} 3$ to $\mathrm{d} 6$. In particular, IX and LS animals had a $103 \%$ increase in uterine mass as compared to LC mice, which had an $87 \%$ increase between the two measurement stages. However, analyzing the square root of uterine mass (the transformation that made the variances within $\mathrm{d} 3$ and $\mathrm{d} 6$ similar) revealed no significance $(P<.32)$ for this interaction.

Adjustment for Number of Corpora Lutea. Means, tests of significance for contrasts, and the regression coefficients for $\mathbf{d} 3$ and $d \mathbf{6}$ data are presented in Table 5. For brevity, only data for uterine mass, uterine blood volume, and uterine mass relative to body mass are presented. Uterine mass and uterine mass/body mass were not transformed for these analyses because

Table 4. Least squares means by day of pregnancy with SE of means

\begin{tabular}{lccc}
\hline \hline Item & Day 3 & Day 6 & SEM \\
\hline Body mass, g & 26.65 & 28.31 & .18 \\
Uterine mass, g & .207 & .409 & .003 \\
Tr' uterine mass, g & .452 & .634 & .004 \\
Corpora lutea & 14.40 & 14.68 & .23 \\
Uterine blood, $\mu \mathrm{L}$ & 9.90 & 15.86 & .18 \\
Uterine mass/body mass, $\%$ & .77 & 1.44 & .01 \\
Tra uterine mass/body mass, \% & .88 & 1.19 & .01 \\
Uterine blood/blood mass, $\mu \mathrm{L} / \mathrm{g}$ & .369 & .558 & .006 \\
Uterine blood/uterine mass, $\mu \mathrm{L} / \mathrm{g}$ & 47.00 & 38.99 & 1.04 \\
\hline
\end{tabular}

${ }^{\mathrm{a}} \mathrm{Tr}=$ square-root transformation of the variable. they were done separately for d-3 and d-6 data. The regressions were tested for interaction with the selection criteria; there were no differences between criteria for the regressions, and thus only a common regression was fitted in each analysis.

Number of corpora lutea was a significant source of variation for uterine variables at both 3 and $6 \mathrm{~d}$. It is not surprising that the regression was significant at $d$ 6 because this is after implantation is completed. More embryos would probably stimulate the uterus to try and accommodate their demands for nutrients and space. Although the size of the regressions was smaller at $d 3$ than at $d 6$, number of corpora lutea was nonetheless a significant source of variability for uterine measurements already at $d 3$. Either there are pre-ovulatory factors that affect both number of ovulations and uterine development, causing a positive correlation between them, or there are stimulatory effects on the uterus either by the number of corpora lutea or by pre-implantation embryos.

After adjustment for number of corpora lutea, there was a significant (at least $P<.06$ ) contrast of IX, LS, and UT vs LC for uterine mass, although not at the high level of significance found in the unadjusted data. Differences in uterine mass relative to body mass were not important after adjustment. Uterine blood was higher $(P<.03)$ in IX, LS, and UT vs LC at d 6 but not at $\mathrm{d} 3$ after adjustment for number of ovulations.

Discussion. Differences in number of corpora lutea between the four criteria of selection were consistent with those observed in previous studies of these lines (Gion et al., 1990; Al-Shorepy et al., 1992; Clutter et al., 1994). Because there were large significant differences in ovulation rate between mice from the four selection criteria, caution must be exercised in evaluating the results using the adjustment for number of corpora lutea. Whether there are systematic differences in uterine physiology beyond those induced by number of corpora lutea or number of embryos is the question. More of the differences observed in the analysis unadjusted for number of 
Table 5. Least squares means by selection criterion, SE of the means, significance levels of contrasts of the criterion means, and regressions on number of corpora lutea for characteristics measured at day 3 and day 6 of gestation

\begin{tabular}{|c|c|c|c|c|c|c|c|c|c|}
\hline \multirow[b]{2}{*}{ Item } & \multirow[b]{2}{*}{$b^{c}$} & \multicolumn{4}{|c|}{ Criterion $^{a}$} & \multirow[b]{2}{*}{ SEM } & \multicolumn{3}{|c|}{ Significance level of contrast ${ }^{b}$} \\
\hline & & IX & LS & UT & $\mathrm{LC}$ & & 1 & 2 & 3 \\
\hline \multicolumn{10}{|l|}{ Day 3} \\
\hline Uterine mass, $\mathrm{g}$ & .0024 & .213 & .222 & .207 & .184 & .009 & .03 & .35 & .55 \\
\hline Uterine blood, $\mu \mathrm{L}$ & .235 & 10.53 & 10.64 & 9.56 & 8.80 & .73 & .14 & .28 & .92 \\
\hline Uterine mass/body mass, \% & .0052 & .77 & .80 & .79 & .73 & .03 & .19 & .86 & .47 \\
\hline \multicolumn{10}{|l|}{ Day 6} \\
\hline Uterine mass, $\mathrm{g}$ & .0095 & .426 & .446 & .403 & .361 & .022 & .06 & .25 & .51 \\
\hline Uterine blood, $\mu \mathrm{L}$ & .393 & 16.78 & 16.51 & 15.81 & 14.36 & .55 & .03 & .24 & .73 \\
\hline Uterine mass/body mass, \% & .020 & 1.44 & 1.52 & 1.44 & 1.35 & .08 & .31 & .67 & .52 \\
\hline
\end{tabular}

${ }^{\text {a IX }}=$ index; $\mathrm{LS}=$ litter size; UT = uterine capacity; LC = control.

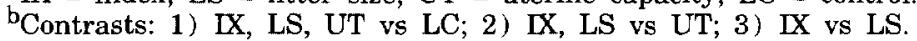

${ }^{\mathrm{c}}$ Regression on number of corpora lutea; all significant $P<.01$.

corpora lutea were explained by variation in number of corpora lutea in the animals at $d 3$ than at $d 6$. We would expect the opposite given the longer time and the effect of implantation.

It seems that adjustment for number of ovulations is adjusting for some of the variation between the selection lines that is caused by a systematic common effect on both ovulation rate and uterine physiology. Thus, the analyses of the unadjusted data are deemed better for evaluating differences between these selection criteria in uterine measurements.

Several studies with different species have observed an increase in uterine dimensions and mass and(or) uterine blood volume or blood flow in pregnant females as affected by the number of implantations or number of fetuses being carried. Spruill and Eisen (1988) have observed this in mice; McRae and Heap (1988) in rats; Hard and Anderson (1982) and Wu et al. (1987) in pigs; Christian and Prior (1978) in sheep; and Ferrell and Reynolds (1992) in cattle.

Physical reduction of uterine space or uterine blood supply per embryo and its subsequent limiting effect on fetal development or survival has been reported by Senger et al. (1967) in mice; Antebi et al. (1991) in rats; and Webel and Dziuk (1974), and Fenton et al. $(1970,1972)$ in pigs.

In the present data, there was no evidence for differences between the selection lines in uterine blood per unit of uterine tissue. Rather, differences existed in uterine mass, and the same differences were significant for uterine blood volume. The lines that had a history of selection for litter size or some component (LS, IX, and UT) had significantly larger uterine mass per unit of body mass. Thus, it seems that selection has increased uterine mass and concomitantly uterine blood volume to support larger litter sizes but has not increased blood volume relative to uterine mass.

This increased size of the uterus with the proportionally larger volume of blood could be at least one of the causes for enhanced stage of development ob- served in 3.5-d embryos of these same lines by AlShorepy et al. (1992). Selection (IX, LS, and UT) as compared to the unselected LC advanced the mean stage of development for embryos flushed from the left horn; a similar, but not significant, shift in development was observed for embryos recovered from the right horn. There also tended to be less variability in stage of embryos within a litter. We speculate that the increased blood has caused less stress and competition among embryos, and hence less variability and more rapid development in the IX, LS, and UT lines.

Clutter et al. (1994) estimated mean capacities for the left and right uterine horns in unilaterally ovariectomized females in these same selection lines. The means of the two horns were 11.87, 12.84, 11.90, and 10.46 fetuses for IX, LS, UT, and LC, respectively. The average of IX, LS, and UT differed significantly from LC, but no significant differences were detected among IX, LS, and UT. In agreement are the significant differences between the three selection criteria and LC for uterine mass and uterine blood volume. Compared to LC, IX and UT selections were 13 to $14 \%$ higher and LS was $23 \%$ higher for uterine capacity as reported by Clutter et al. (1994). The most comparable percentages in the uterine measurements were the 10\% (IX and UT) and 20\% (LS) advantages over LC for uterine mass/body mass.

Clutter et al. (1994) reported that ova success (proportion of ova that becomes pups) was .78 for UT as compared to .71 to .73 for IX, LS, and LC. Evidently other factors beyond simply uterine blood contribute to the success rate of ova that are shed, because UT did not stand out among the lines of the three selection criteria as superior in uterine measurements.

Uterine size has been studied in other works with rodents. Spruill and Eisen (1988) reported that mice in a line selected for and demonstrating considerable response in litter size had longer uteri at day of mating but did not have larger uterine mass than mice in an unselected control. After 6 and $14 \mathrm{~d}$ of pregnancy, mice in the selected line had both larger 
uterine mass and longer uteri than the controls; however, these differences were removed when the data were adjusted for number of fetuses. Larson and Foote (1972) concluded that uterine blood flow in rabbits is a limiting factor for fetal survival and explains part of the difference between young and aged does.

Comparison of uterine mass or volume as an explanation for differences in uterine capacity and ova success between different selection lines of pigs has not been conclusive. Gama and Johnson (1993) compared gilts from a line selected for litter size that had an advantage for number born with gilts from an unselected companion control line. Although the line with higher litter size produced a larger mean number of fetuses in unilaterally hysterectomized-ovariectomized gilts (thus greater uterine capacity) than the control, there were not increases in uterine dimensions or uterine mass of intact, unaltered gilts.

In conclusion, greater uterine mass and concomitantly greater uterine blood volume may have been partly responsible for greater uterine capacity resulting from LS, IX, and UT selections in mice. Although body mass also increased with selection for litter size or its components in mice, there was a proportionately greater increase in uterine mass, which likely contributed to enhanced uterine capacity.

\section{Implications}

Differences in uterine capacity of mice can be created by selection. Differences in uterine mass, and hence blood volume, may explain at least part of the advantages in uterine capacity of selected lines of mice. Better methods to increase uterine capacity, where limiting in animal populations, are needed.

\section{Literature Cited}

Al-Shorepy, S. A., A. C. Clutter, R. M. Blair, and M. K. Nielsen. 1992. Effects of three methods of selection for litter size in mice on pre-implantation embryonic development. Biol. Reprod. 46 : 958.

Antebi, E., J. M. Lehmann, A. Gingold, and M. Nobel. 1991. The effect of impairment of blood supply to the rat uterus. Int. J. Fertil. 36:376.

Bakker, H., J. H. Wallinga, and R. D. Politiek. 1978. Reproduction and body weight of mice after long-term selection for large litter size. J. Anim. Sci. 46:1572.
Bennett, G. L., and K. A. Leymaster. 1989. Integration of ovulation rate, potential embryonic viability and uterine capacity into a model of litter size in swine. J. Anim. Sci. 67:1230.

Christenson, R. K., and R. L. Prior. 1978. Uterine blood flow and nutrient uptake during late gestation in ewes with different number of fetuses. J. Anim. Sci. 46:189.

Clutter, A. C., Y. L. Kochera Kirby, and M. K. Nielsen. 1994. Uterine capacity and ovulation rate in mice selected 21 generations on alternative criteria to increase litter size. J. Anim. Sci. 72:577.

Clutter, A. C., M. K. Nielsen, and R. K. Johnson. 1990. Alternative methods of selection for litter size in mice: I. Characterization of base population and development of methods. J. Anim. Sci. 68:3536.

Fenton, F. R., F. W. Bazer, O. W. Robison, and L. C. Ulberg. 1970. Effect of quantity of uterus on uterine capacity in gilts. J. Anim. Sci. 31:104.

Fenton, F. R., F. L. Schwartz, F. W. Bazer, O. W. Robison, and L. C. Ulberg. 1972. Stage of gestation when uterine capacity limits embryo survival in gilts. J. Anim. Sci. 35:383.

Ferrel, C. L., and L. P. Reynolds. 1992. Uterine and umbilical blood flows and net nutrient uptake by fetuses and uteroplacental tissues of cows gravid with either single or twin fetuses. J. Anim. Sci. 70:426.

Gama, L.T.T., and R. K. Johnson. 1993. Changes in ovulation rate, uterine capacity, uterine dimensions, and parity effects with selection for litter size in swine. J. Anim. Sci. 71:608.

Gion, J. M., A. C. Clutter, and M. K. Nielsen. 1990. Alternative methods of selection for litter size in mice: II. Response to thirteen generations of selection. J. Anim. Sci. 68:3543.

Hard, D. L., and L. L. Anderson. 1982. Interaction of maternal blood volume and uterine blood flow with porcine fetal development. Biol Reprod. 27:79.

Joakimsen, O., and R. L. Baker. 1977. Selection for litter size in mice. Acta Agric. Scand. 27:301.

Kirby, Y. K., and M. K. Nielsen. 1993. Alternative methods of selection for litter size in mice: III. Response to twenty-one generations of selection. J. Anim. Sci. 71:571.

Larson, L. L., and R. H. Foote. 1972. Uterine blood flow in young and aged rabbits. Soc. Exp. Biol. Med. 141:67.

McRae, A. C., and R. B. Heap. 1988. Uterine vascular permeability, blood flow and extracellular fluid space during implantation in rats. J. Reprod. Fertil. 82:617.

Senger, P. L., E. D. Lose, and L. C. Ulberg. 1967. Reduced blood supply to the uterus as a cause for early embryonic death in the mouse. J. Exp. Zool. 165:337.

Spruill, S. E., and E. J. Eisen. 1988. Ovulation rate and embryo survival during gestation and the effects of ovariectomy on maternal nurturing ability. J. Anim. Sci. 61:834.

Tanaka, N., L. L. Espey, and H. Okamura. 1989. Increase in ovarian blood volume during ovulation in the gonadotropin-primed immature rat. Biol. Reprod. 40:762.

Webel, S. K. and P. J. Dziuk. 1974. Effect of stage of gestation and uterine space on prenatal survival in the pig. J. Anim. Sci. 38: 960.

Wu, M. C., M. D. Hentzel, and P. J. Dziuk. 1987. Relationships between uterine length and number of fetuses and prenatal mortality in pigs. J. Anim. Sci. 65:762. 